\title{
5.2 mW Single-Mode Power from a Coupled-Resonator Vertical-Cavity Laser
}

\author{
A.J. Fischer, K.D. Choquette, W.W. Chow, A.A. Allerman, and K.M. Geib \\ Center for Compound Semiconductor Science and Technology, Sandia National \\ Laboratories, Albuquerque, NM 87185
}

\begin{abstract}
:
We have achieved $5.2 \mathrm{~mW}$ of single fundamental-mode power from a coupledresonator vertical-cavity laser. The enhanced mode selectivity is due to gain profiling combined with current-induced changes in cavity coupling.
\end{abstract}

\section{Corresponding Author:}

Arthur J. Fischer

Tel. (505) 844-6543

Fax. (505) 844-8985

Email: ajfisch@sandia.gov 


\section{DISCLAIMER}

This report was prepared as an account of work sponsored by an agency of the United States Government. Neither the United States Government nor any agency thereof, nor any of their employees, make any warranty, express or implied, or assumes any legal liability or responsibility for the accuracy, completeness, or usefulness of any information, apparatus, product, or process disclosed, or represents that its use would not infringe privately owned rights. Reference herein to any specific commercial product, process, or service by trade name, trademark, manufacturer, or otherwise does not necessarily constitute or imply its endorsement, recommendation, or favoring by the United States Government or any agency thereof. The views and opinions of authors expressed herein do not necessarily state or reflect those of the United States Government or any agency thereof. 


\section{DISCLAIMER}

Portions of this document may be illegible in electronic image products. Images are produced from the best available original document. 


\title{
5.2 mW Single-Mode Power from a Coupled-Resonator 3 S I Vertical-Cavity Laser
}

\author{
A.J. Fischer, K.D. Choquette, W.W. Chow, A.A. Allerman, and K.M. Geib \\ Center for Compound Semiconductor Science and Technology, Sandia National \\ Laboratories, Albuquerque, NM 87185
}

Vertical-cavity surface-emitting lasers (VCSELs) which emit into a single optical mode are increasingly sought for emerging VCSEL applications, which include data communications with single-mode fiber, bar code scanning, laser printing, optical read/write heads, and modulation spectroscopy. We have achieved a record high fundamental-mode power of $5.2 \mathrm{~mW}$ from our coupled-resonator vertical-cavity lasers (CRVCLs) [1]. In conventional VCSELs, the extent to which the gain volume may be increased is limited by the onset of multi-mode operation. Our results indicate that this limitation is circumvented in a coupledresonator device allowing high power fundamental-mode operation.

As shown in Fig. 1, the coupled-resonator is composed of a bottom p-type distributed Bragg reflector (DBR) with 35 periods, a middle n-type DBR with 11.5 periods, and a top ptype DBR with 22 periods [2]. The top and bottom one-wavelength cavities each contain five $8 \mathrm{~nm} \mathrm{GaAs}$ quantum wells. The device was fabricated using a two-tier etch with two metal ring contacts on the top as well as a back side contact. A $6 \times 6 \mu \mathrm{m}$ proton implant was used for current injection in the top cavity while a $10 \times 10 \mu \mathrm{m}$ oxide aperture was used in the bottom cavity.

Figure 2 shows a light-current curve for a CRVCL device where the implant cavity current is fixed at $5.0 \mathrm{~mA}$ with a varying oxide cavity current. The inset of the figure shows the lasing spectrum with $\mathrm{I}_{\text {implant }}=5.0 \mathrm{~mA}$ and $\mathrm{I}_{\text {oxide }}=13.7 \mathrm{~mA}$. The main lasing peak is at $853.8 \mathrm{~nm}$ and the next largest intensity higher-order mode is $32 \mathrm{~dB}$ lower. At $13.7 \mathrm{~mA}$, the device is lasing single-mode with an output power of $5.2 \mathrm{~mW}$.

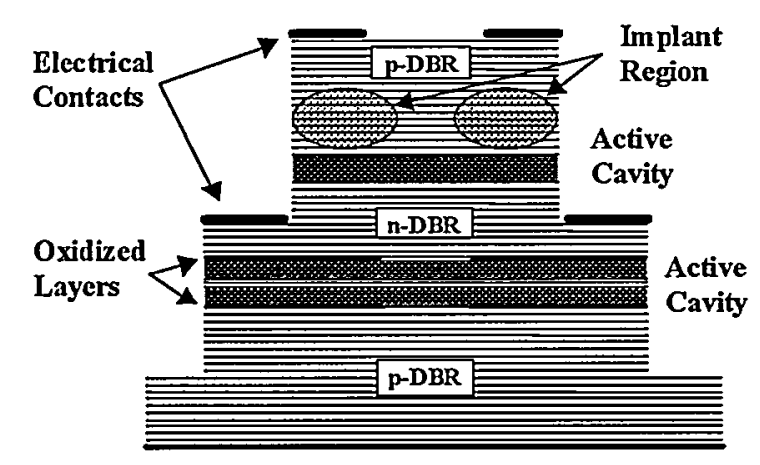

Backside Contact

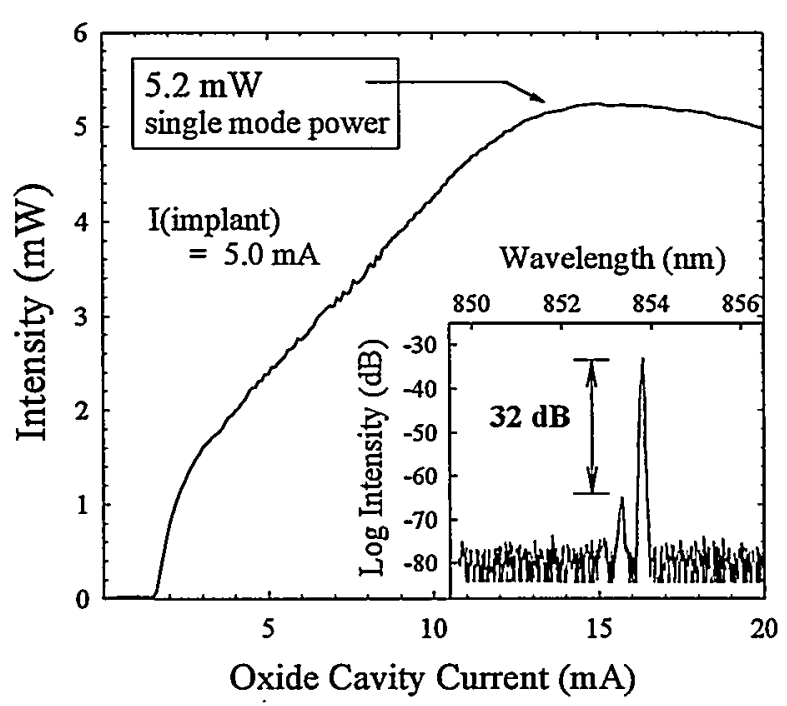

Figure 2: Light-current curve showing $5.2 \mathrm{~mW}$ single-mode
power. The inset shows the single mode lasing spectrum. spectrum.

Figure 1: Schematic Diagram of Coupled-Resonator Vertical-Cavity Laser. Note the use of both oxide and implant current apertures. 


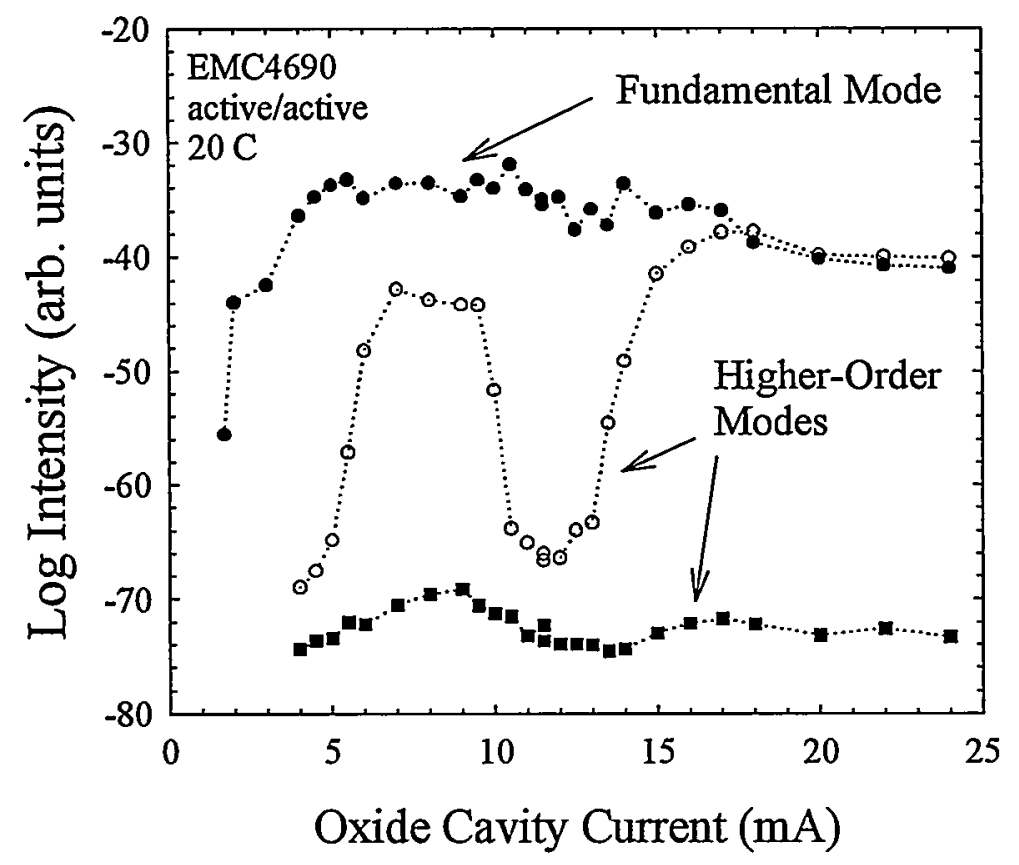

Figure 3. Emission wavelength plotted as a function of oxide cavity current for all observable cavity modes at an implant cavity current of $5.0 \mathrm{~mA}$.

Figure 3 shows the lasing wavelength for all detectable transverse modes as a function of oxide cavity current with the implant cavity biased for single-mode operation. The device begins lasing single-mode near threshold and, at $6 \mathrm{~mA}$, a second mode appears. Near $12 \mathrm{~mA}$ this second mode decreases and we observe our record high $5.2 \mathrm{~mW}$ single-mode power. Above $15 \mathrm{~mA}$ the device operates multi-mode.

Modeling of the CRVCL indicates that gain profiling combined with coupled-cavity modal selection enables high fundamental power operation. Fundamental mode discrimination is enhanced by the gain profiling provided by the top $6 \mu \mathrm{m}$ diameter implant. Independent current injection into the two cavities allows selection of the fundamental coupled mode. Note that high power fundamental-mode operation is achieved with an oxide transverse cavity size of $10 \mu \mathrm{m}$ which would be multi-mode in a conventional VCSEL.

Further experimental and theoretical work is in progress to understand the changes in coupling and to optimize these structures. Future devices are expected to show even larger single-mode powers. The flexibility provided by these three-terminal coupled-cavity devices will enable high-speed switching applications where high single-mode power is required [3].

This research was performed at Sandia National Laboratories, a multiprogram laboratory operated by Sandia Corporation, for the United States Department of Energy under contract No. DE-AC04-94AL85000.

\section{References}

[1] K.D. Choquette, W.W. Chow, H.Q. Hou, K.M. Geib, and B.E. Hammons, "Coupled-Resonator Vertical-Cavity Laser Diode," Proceeding of the SPIE- The International Society for Optical Engineering 3286, 134 (1998).

[2] A.J. Fischer, K.D. Choquette, W.W. Chow, H.Q. Hou, and K.M. Geib, "Coupled-Resonator Vertical-Cavity Laser Diode,"Appl. Phys. Lett. 75, 3020 (1999).

[3] A.J. Fischer, W.W. Chow, K.D. Choquette, A.A. Allerman, and K.M. Geib, "Q-switched Operation of a Coupled-Resonator Vertical-Cavity Laser Diode," Appl. Phys. Lett. 76, 1975 (2000). 